\title{
An overview of factors affecting dengue transmission in Asian region and its predictive models
}

\author{
Roopa Rani Samal \\ Insect Pest and Vector Laboratory, Department of Zoology, Acharya Narendra Dev College, \\ University of Delhi, India. \\ Saiesha Gupta \\ The Benenden School (TBS), Kent, United Kingdom. \\ Sarita Kumar* \\ Insect Pest and Vector Laboratory, Department of Zoology, Acharya Narendra Dev College, \\ University of Delhi, India. \\ ${ }^{*}$ Corresponding author. E. mail: saritakumar@andc.du.ac.in
}

\section{How to Cite}

Samal, R. R. et al. (2020). An overview of factors affecting dengue transmission in Asian region and its predictive models. Journal of Applied and Natural Science, 12(3): 460 - 470. https://doi.org/10.31018/jans.v12i3.2360

\begin{abstract}
Among various mosquito-borne diseases, dengue is one of the most prevalent and quickly spreading diseases primarily transmitted by Aedes aegypti and Aedes albopictus. This review discusses the dengue epidemics in Asian countries with a focus on India and recognizes various climatic, socio-economic and demographic factors and their complex interaction, involved in dengue expansion. The impact of climatic factors, such as temperature, moisture and precipitation has been elucidated on the mosquito breeding and disease outbreaks; demonstrating a linear correlation of ambient temperature and humidity with dengue transmission, in contrast with the uncertain association of rainfall. Multifarious empirical models have been developed for estimating the climatic effects on dengue and are used as a baseline to assess the impact on future infections. However, the spatiotemporal distribution of dengue cases can only be predicted best using dynamic modelling based on a blend of long-term climatic data, vector ecology, and multiple etiological parameters. The human economic profile, migration and the behavioural pattern towards the epidemic have also impacted dengue transmission. Moreover, the impoverished countries are facing higher risks due to the lack of resources for proper medical care and mosquito management measures. Thus, advanced and confirmatory vector control interventions, increased awareness of Aedes-borne diseases, and adequate decision and policies may play a key role to prepare and combat the disease incidences across varied geographic range. Moreover, the increasing support for the research and development along with regular monitoring, can help recognize the current and predict the future distributions of Aedes and DENV better.
\end{abstract}

Keywords: Aedes, Climate change, Dengue, Predicting models, Socio-economic factors

\section{INTRODUCTION}

Dengue, an Aedes-borne disease, is one of the most prevalent mosquito-borne diseases nowadays. Since the past few decades, the dengue incidence throughout the world has increased at a large scale despite fruitful intercession efforts, enhanced sanitation practices and developments in medical care. Ironically, apart from frequent outbreaks in the dengue-endemic areas, the emergence of disease in unexposed regions has resulted in an increased count of fatalities. As per reports of the World Health Organization (WHO, 2019a), South-East Asia and WHO regions of the Americas are considered major hotspots recording substantial dengue cases. The Organization has listed 129 countries; primarily Asian and American countries; which are endemic to the risk of dengue and distress nearly 3.97 billion people (Brady et al., 2012; Bhatt et al., 2013; WHO, 2020a). With roughly 50\% world's population at risk of dengue and 100-400 million annual infections; the disease is on the rampant increase. The rise in dengue incidences can be attributed to multifaceted reasons, but the prospective driving force behind spreading disease worldwide could be rapid globalization, mass mobility, unplanned urbanization, and environmental changes (Bhatt et al., 2013). The climatic changes in multiple regions of the world, facilitating mosquito breeding and increased global travel patterns transmitting novel dengue virus serotypes to new topographical areas; have been contributing majorly in its global expansion. All these possible grounds have been supported by the lack of effective medication and non-availability of a successful vac- 
cine against the disease.

Dengue, principally spread by $A e$. aegypti, is a disease of sub-tropical and tropical climates, habitually in semiurban and urban areas. However, Ae. albopictus, commonly found in peri-urban and rural environments, has expanded its range to temperate regions. Mathematical and geographical models based on climate change projections in 2085 have predicted occurrence of 5-6 billion dengue cases in comparison to 3.5 billion incidences in the absence of serious climatic changes (Hales et al., 2002). The anticipated climatic variations, which are likely to affect the distribution and vectorial competence of Aedes, can have a noteworthy impact on the dengue epidemiology. The data implicate that climate change, prospectively, might raise the total geographical area with warmer environmental conditions suited for dengue vector breeding and dengue fever transmission putting a greater human population to danger. Thus, it is increasingly significant to understand and analyze the climatic and non-climatic impacts, that could possibly affect the complex associations between the vector, pathogen and host expanding the dengue occurrence globally.

\section{DENGUE EPIDEMIC IN ASIA}

Dengue, caused by the dengue virus (DENV), was first recognized in 1779 in Asia, Africa and North America (Howe, 1977). The earliest records of a dengue-like infection date back to 265 to 420 A.D. during the Chin Dynasty, when a disease connected with waterassociated flying insects was described as 'water poison' (Nobuchi, 1979). Later, several countries encountered outbreaks of dengue-like diseases, yet until today it is uncertain whether it was dengue (McSherry, 1982). Thereafter, the impact of dengue-like infection, from 1779 to 1940 , consisted of irregular epidemics, and finally, dengue resurged as a global epidemic in Southeast Asia around the time of World War II, due to increased transmissions of mosquito-borne diseases.

The rise in dengue transmission led to the resurgence of multiple DENV serotypes in Southeast Asia, resulting in the emergence of dengue haemorrhagic fever (DHF), more severe clinical manifestation of dengue (Gubler and Trent, 1993). Severe dengue was first documented in 1953-1954 when Thailand and Philippines encountered dengue epidemics. Within two decades, the disease spread to numerous Southeast Asian countries; India, Pakistan, Maldives, Sri Lanka, and China paving its way to other tropical countries around the globe. During the 1980s, and 1990s, the transmission of the Ae. aegypti and the dengue viruses have seen a surge in geographical distribution, and frequency of epidemics (Gubler, 1997). One such dengue epidemic was reported in Singapore during 2005, with a record 14,006 cases and $0.19 \%$ fatality rate
(Koh et al., 2008). In the subsequent year, epidemics occurred in India and Pakistan risking the huge number of human lives (Ghani et al., 2008). In 2011, Philippines experienced 18,885 cases, $5.24 \%$ higher than the previous year and a total of 52,008 cases emerged in Thailand (Win, 2013), denoting the significant rise in the rate of dengue transmission. Outbreaks continued to intensify in most of the Southeast Asian countries, with the dengue deaths tripling in Malaysia during 2012-2014 and approximately 180,000 cases and 301 fatalities in Sri Lanka in 2017 (Win, 2013).

A dramatic increase in the dengue expansion from nine countries in the 1970 s to 129 countries in 2019; made dengue as one of the world's top 10 public health threats (WHO, 2020a). The year 2019 has been recorded as worst-ever year in terms of dengue documenting a vast surge in dengue cases resulting in the largest number of dengue cases ever reported globally, affecting almost all regions. In fact, dengue transmission was recorded in Afghanistan for the first time in 2019 (WHO, 2020b). As expected, Asia accounted for approximately $70 \%$ of the reported global cases, with a nationwide endemic in Bangladesh being the direst due to the limited healthcare and high population density in the country. Malaysia encountered a total of $1,31,000$ cases, Philippines had 4,20,000 and Vietnam recorded 3,20,000 cases (WHO, 2020b).

Remarkably, the year 2020 has also seen a vast majority of cases, despite the Covid-19 pandemic, although lower than the previous year. Malaysia has reported 50,511 cases thus far, a 6,308 decrease from the same period in 2019. Additionally, the Philippines has seen a $94 \%$ fall in comparison to the same period last year (WHO, 2019b). Although lower than the last year, it is estimated that dengue still poses a risk of infection to 3.9 billion people worldwide (WHO, 2020b).

\section{DENGUE INCIDENCES IN INDIA}

In India, Ae. aegypti and Ae. albopictus are two main competent vectors for dengue virus, though principally Ae. aegypti is responsible for DENV transmission through a human-mosquito-human cycle, with no human-human transmission (Gubler, 1998). The national dengue data integration and analysis of dengue cases in India during 2015-2019, facilitated by National Vector Borne Disease Control Programme (NVBDCP) aided by NIV (National Institute of Virology), reveals highest incidences in 2017 (Fig. 1).

The records showed the prevalence of dengue in almost all the Indian states and Union Territories indicating the presence of suitable environmental conditions for vector breeding and virus transmission. The major dengue incidences in 2019, however, have been documented from the States of Gujarat, Maharashtra, Raja- 
Samal, R. R. et al. / J. Appl. \& Nat. Sci. 12(3): 460 - 470 (2020)

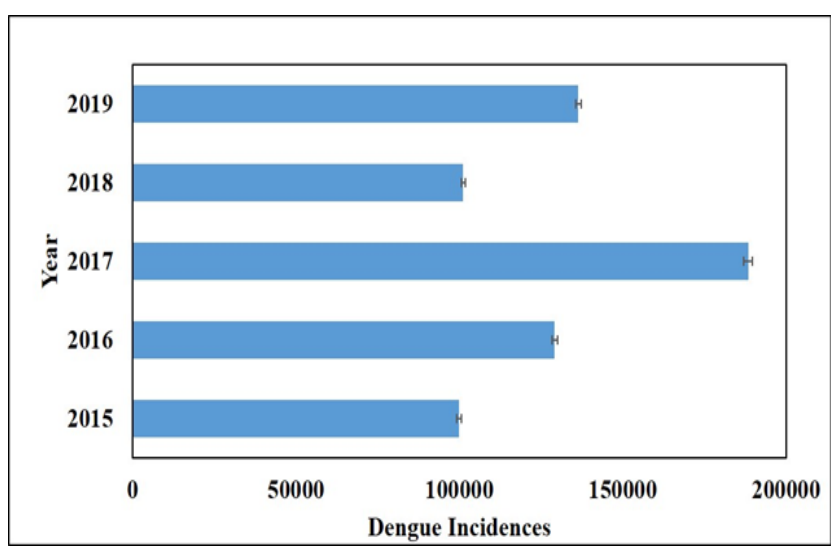

Fig. 1. Dengue Cases in India during 2015-2019 (Based on data procured from NVBDCP, 2020; https://nvbdcp.go v.in/index4.php?lang=1\&level=0\&linkid=431\&lid=3715)

sthan, Karnataka, Telangana, Uttarakhand and Uttar Pradesh (Fig. 2).

The first dengue outbreak in India was reported in 1963 in the Calcutta City (now Kolkata), West Bengal, while the first dengue epidemiology was documented in 1970 in the Madras City (now Chennai), Tamil Nadu (Ramakrishnan et al., 1964). The occurrence of succeeding dengue outbreaks have been recorded in different regions of India, demonstrating the quick spread of the disease (Chaturvedi and Nagar, 2008). In the early 2000s, nevertheless, dengue was restricted to a few Southern States (Karnataka, Maharashtra, Pondicherry and Tamil Nadu), a few Northern States (Haryana, Punjab and Rajasthan) and two Union territories (Delhi and Chandigarh) (Chakravarti et al., 2012). Since 2001, a significant rise in the total number of dengue cases has been reported in India. Unfortunately, a major 'urban to rural' shift in the geographical range of the disease along with the rising cases and severity, has augmented the associated problems (Arunachalam et al., 2004). The prime factors recognized for dengue expansion have been listed as unscheduled urbanization, impulsive development, wide-ranging ecological features, diverse environmental parameters, population immunological attributes and host-pathogen interactions. Moreover, inadequate and ineffective vector control intercessions have shaped conditions which proved beneficial not only for the mosquito vectors but also dengue virus transmission. The emergence of four distinct serotypes of DENV (DEN-1, DEN-2, DEN-3 and DEN-4) has further augmented the recurrence and the severity of the disease (Pandya, 1982). Though, the fifth variant of DENV; spread by Ae. nivalis through the sylvatic cycle and presumed to be the result of high mutation frequencies, natural selection and genetic recombination bottlenecks; has been isolated and sequenced in

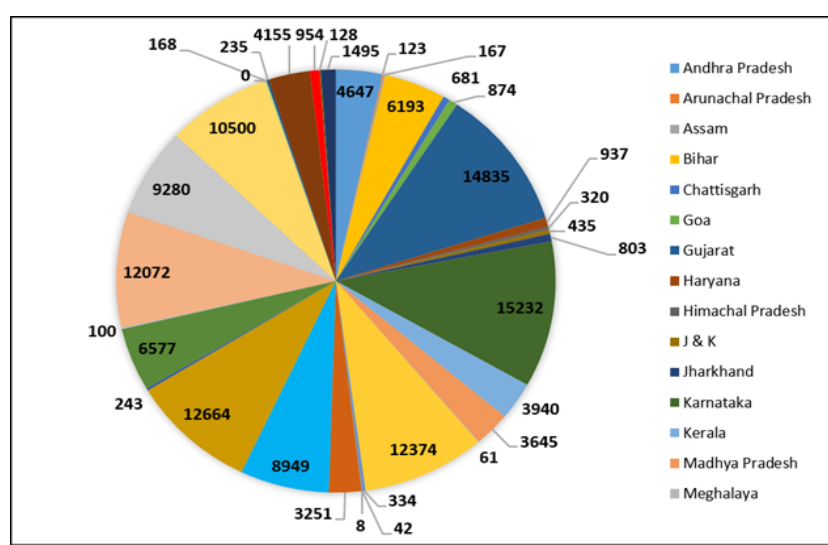

Fig. 2. Epidemiological profile of dengue fever in India in the year 2019 (Based on data procured from NVBDCP, 2020; https://nvbdcp.gov.in/index4.phplang=1\&level=0\&li nkid=431\&lid=3715)

Malaysia in October 2013, there is no indication of its presence in India (Mustafa et al., 2015).

\section{IMPACT OF CLIMATE CHANGE ON DENGUE TRANSMISSION}

Epidemiological trilogy of dengue includes human being, DENV and $A e$. aegypti alongside their interfaces with the environment. The climate plays a significant role in the disease transmission as ambient temperature, rainfall, and humidity have a direct influence on the breeding and development of Ae. aegypti making the disease climate-sensitive. Yet, insignificant correlation between temperature and precipitation specify the complex connection between climatic variables and dengue incidence

Studies have shown a complex connection between the ecology of virus and the ecology of Aedes species (Scott et al., 2000). Various reports have elucidated the impact of global climate change on the mosquito breeding and disease outbreaks (Carrington et al., 2013a; b; c; Chaves et al., 2014); especially relative humidity (Chakravarti and Kumaria, 2005; Thammapalo et al., 2005; Gharbi et al., 2011), rainfall (Hales et al., 2002; Johansson et al., 2009a) and temperature (Chen and Hsiesh, 2012; Descloux et al., 2012; Earnest et al., 2012). A close association of dengue incidence and seasonal patterns in temperature, relative humidity, and rainfall has been detected in Taiwan, Thailand, Brazil and Singapore (Chilkaki and Ishikawa, 2009; Chen and Hsieh, 2012; Texeiera et al., 2013; Andraud et al., 2013). In Korea, Lee et al. (2018) validated a strong correlation between temperature and the potential threat of domestic dengue outbreaks. On the other hand, many investigators have questioned the role of climatic variability as the main factors for the observed expansion of dengue (Gubler et al., 2001; Halstead, 2008). They suggested globali- 


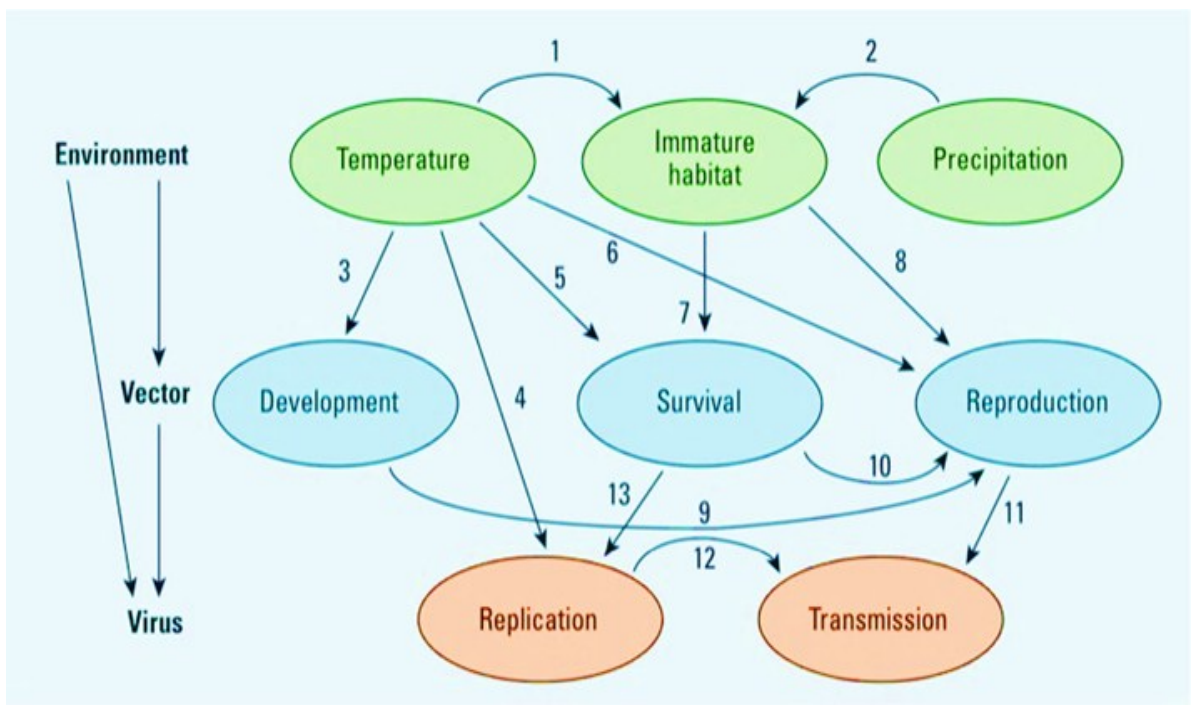

(Source: Morin et al. 2013)

Fig. 3. Biophysical influences on DENV ecology, showing the interactions between climate variables, vectors, and the virus. Numbers identify relationships between variables. Habitat availability for mosquito larvae influenced by temperature through evaporation and transpiration (1) and incoming precipitation (2). Temperature is a major regulator of mosquito development (3), viral replication within infected mosquitoes (4), mosquito survival (5), and the reproductive behaviour of mosquitoes (6). Habitat availability is required for immature mosquito survival (7) and reproduction of adult mosquitoes (8). Faster mosquito development and increased survival will accelerate mosquito reproduction (9 and 10). Increased mosquito reproduction enhances the likelihood of transmission by increasing the number of blood feedings (11), whereas faster viral replication increases transmission by shortening the extrinsic incubation period (12). Last, increased survival of the adult mosquito increases the amount of viral replication (13).

zation, urbanization with population growth and the inadequate control measures as the three chief drivers responsible for dengue expansion.

Temperature and dengue: Ambient temperature is considered the most critical climatic factor in dengue transmission, being the limiting factor for development rate of Aedes. The prevailing temperature can exert non-linear converse effects on the possibility of dengue risk. The higher dengue risk in tropical and subtropical countries than temperate regions may be attributed to the higher temperature conditions which quicken the mosquito development and DENV incubation time, especially in vector-endemic areas (Focks et al., 1995; Kuno, 1995; Patz et al., 1996; McMichael and Haines, 1997). Nevertheless, extreme and intense heat can also augment the mosquito mortality declining the dengue hazard (Hii et al., 2009). In Taiwan, Chen and Hsieh (2012) inspected the impact of temperature variation on dengue transmission dynamics in Ae. aegypti. They deduced the importance of temperature in the vector-host interaction and suggested that the existence of $28{ }^{\circ} \mathrm{C}$ temperature can peak the risk of dengue transmission.

Pinto et al. (2011) computed the impact of climatic variables on the occurrence of dengue in Singapore and demonstrated that the inconsistent temperature might act as the best indicator and driver for the growing dengue incidences. They elucidated the maximum probability of the disease occurrence during July-
September with an average rise of $22.2-184.6 \%$ dengue cases for every $2-10{ }^{\circ} \mathrm{C}$ of variation of the maximum temperature during an average increase of 26.1$230.3 \%$ for every $2-10{ }^{\circ} \mathrm{C}$ of variation of the minimum temperature during April-August. The regression model study by Shil et al. (2019) obtained a positive relationship with the minimum temperature predictors with the dengue transmission during the early summer in Southern Taiwan.

Rainfall and dengue: In contrast with the unswerving and reliable association of dengue incidences with temperature; the association with rainfall has fluctuated from weak or no connection and is still uncertain (Gomes et al., 2012). A few reports have demonstrated conflicting non-linear impact on dengue menace in context to annual rainfall due to swift sweeping away of mosquito developmental stages during heavy rainfall while creating long-lasting breeding habitats as residual standing water bodies (McMichael et al., 2006; Watson et al., 2007; Hii et al., 2009; Githeko, 2012; Sarfraz et al., 2012). A major reduction in vector population has been observed just after 10 days of heavy precipitation (Watson et al., 2007).

The impact of rainfall on the dengue occurrence in the most affected states of India has been investigated during 2010-2016 (Shil, 2019). Through Spatiotemporal analysis, he deduced a positive correlation of high rainfall with the number of dengue incidences in the Northern Indian States whereas a negative correla- 
tion with the cases in the Southern Indian States, demonstrating the differential impact of rainfall on dengue transmission. The storage of water during arid and rain-deprived conditions has also been observed to amplify the mosquito breeding and disease transmission (Aziz et al., 2012). A negative relationship of the maximum $24 \mathrm{~h}$ rainfall predictors with the dengue incidences was observed during the early epidemic phase of dengue outbreaks in Taiwan (Yuan et al., 2019). Rainfall has also been found to be significantly associated with dengue occurrence through lag of 13 months; the maximum correlation $(r=0.741)$ was found at the lag of 2 months (Tuladhar et al., 2019). The similar lag effect in the correlation of rainfall and dengue occurrence was reported in Taiwan (Chen and Hsieh, 2012), Cambodia (Choi et al., 2016), Puerto Rico (Johansson et al., 2009b), Singapore (Hii et al., 2009), China (Lu et al., 2009) and Saudi Arabia (Alshehri and Saeed, 2013).

The spatial heterogeneity and non-linear correlations between rainfall and the dengue occurrence have been ascribed to the regional geography, Aedes populations and the species involved (Johanasson et al., 2009a). Involvement of complex pathways and their interaction with other ecological parameters in the rainfall and dengue incidence association has necessitated extensive investigations to elucidate the interface between rainfall and weather conditions, such as wind speed, humidity, water evaporation and cloud cover.

Relative humidity and dengue: A 19-year retrospective study conducted by Ramachandran et al. (2016) in East Delhi, India demonstrated a strong relationship between relative humidity $(\mathrm{RH})$ and dengue cases due to humidity-dependent life span of mosquitoes. Similar conclusions have been deduced by Karim et al. (2012) and Promprou et al. (2011) recording a higher number of dengue cases during the monsoon with higher $\mathrm{RH}$. A 5 -fold increase in the frequency of probable dengue transmissions was obtained when the survival rate of dengue vector rose from 0.80 to 0.95 (Barbazan et al., 2010). The RH and thus, annual vapour pressure has been suggested as the most significant climatic predictor of global dengue occurrence (Hales et al., 2002)

Climate predictive models: Multifarious empirical models have been developed for estimating the climatic effects on dengue and used as a baseline to assess the impact on future prospective infections (Sriprom et al., 2010). However, the results are inconclusive as the most of the studies are short-term and have covered small topographical areas which are expected to be climatically and socio-economically homogenous in contrast to large regions with variable climates (Elliott and Wartenberg, 2004). Forecasting the global climate change over the next few decades (Gubler, 2012; Halasa et al., 2012; Githeko, 2012), the increase in frequency and intensity of these extreme climatic events are more likely to affect dengue transmission globally. Morin et al. (2013) established a hypothesized relationship between Aedes, DENV, and climate to investigate the potential contribution of climatedriven dengue models and deduced complex and dynamic relationships between climate variables and factors influencing dengue transmission (Fig. 3). He suggested to formulate and apply various climatic indicators on the DENV ecology which could strengthen research in the area and help in predicting the climatic effects on dengue prevalence better.

Thus, a better understanding of the impact of climate change on the prevalence of dengue in a particular region is a significant step which could assist in finding the solutions to lessen the impact of disease on communities (Chaves and Koenraadt, 2010). Successful management of future dengue outbreaks requires a thorough understanding of the dynamics of not only virus, host and vector, but also climatic factors specifically in the context of global climate change (Scott et al., 2000).

\section{IMPACT OF SOCIO-DEMOGRAPHIC CHANGES ON DENGUE}

Apart from climatic factors, dengue transmission can be greatly influenced by socio-demographic changes, economic profile and the behavioural pattern towards the epidemic in local habitats (Nagao et al., 2003; Wearing and Rohani, 2006; Tipayamongkholgul and Lisakulruk, 2011; Walker et al., 2011; Hu et al., 2012). In Texas, USA; dengue virus transmission has been narrowed down by the human lifestyle (Reiter et al., 2003). Various statistical modelling studies conducted on the climatic change-dengue association, have implicated the critical reflection on other factors; such as enormous population growth and unplanned urbanization (Gubler, 2011a). They also claimed the major role of urban growth in tropical regions during the past 5 decades on the increase in dengue transmission as it provided the favourable ecological conditions for a rise in Ae. aegypti population and created ideal conditions for transmission of dengue in heavily populated areas. Dengue-infected human movement has been established as another important factor in dengue transmission due to short flight range and day-biting preference of Aedes, questioning the spread of dengue over large distances (Vazquez-Prokopec et al., 2009). Various studies have discussed the importance of humanmediated DENV dispersal in local virus propagation (Adams and Kapan, 2009: Stoddard et al., 2009). Using contact-site cluster investigations, Stoddard et al. (2013) demonstrated the effect of human movement on dengue transmission at the individual as well as collective level; in spatial heterogeneous pattern. They 
showed the rise in dengue risk through visiting places inhabiting infected mosquitoes, irrespective of the distance from their homes; and emphasized the role of social connects in the DENV transmission. In Vietnam, Rabaa et al. (2010) validated that DENV exchange between various provinces and the Ho Chi Minh City urban regions was due to the human movement. Reiner Jr. et al. (2014) suggested social proximity as a good predictor of DENV infection risk and other Aedes-borne diseases (Fig. 4). The impact of social proximity on the dengue transmission suggests that information about social connects of a DENV-infected individual could help in mosquito management more efficiently as the socially structured infected human movement can waste all the control efforts taken in the vicinity of the DENV-infected persons (Scott and Morrison, 2010).

\section{PREDICTING DENGUE OCCURRENCE IN CHANGING CLIMATE}

Many model studies have projected the future prospective distribution of dengue at the global level influenced by the climate change, such as temperature, rainfall and precipitation; social, economic and demographic changes, particularly urbanization; and the human travel and trade (Khormi and Kumar, 2012; Messina et al., 2015).

The prospective geographic dispersal of dengue, its burden and occurrence have been predicted by two basic model approaches; biological and empirical. The biological model, or mechanistic model, analyses the impact of climatic factors on the survival and proficien-

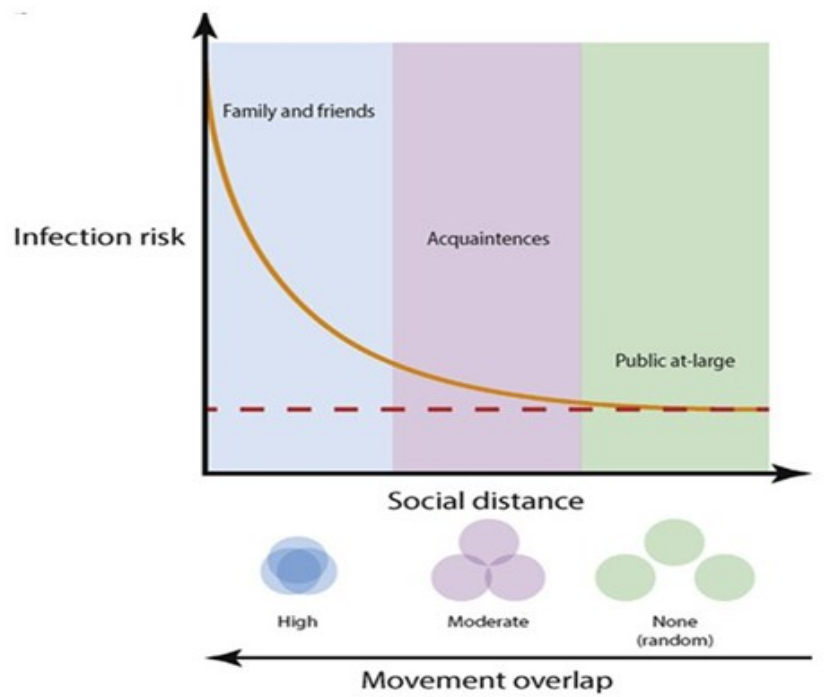

(Source: Reiner Jr. et al., 2014)

Fig. 4. Effect of social proximity on dengue occurrence. The probability of dengue risk decreases as the social distance between people increases until it equals the risk due entirely to an infectious mosquito traversing the distance between the two houses (dashed red line). cy of Aedes population. As the distribution and burden of dengue in different geographical places are correlated with climatic changes and its different parameters; the future dengue outbreaks are predicted. Empirical model; or statistical model; associates the regions with already prevailing dengue incidences and determinants related to prevailing patterns. Anticipated deviations in these factors, thus estimate the future dengue prevalence. Nevertheless, the majority of the vector surveys are piloted in the recognized areas of transmission risk and not marginal areas of transmission. Thus, the lack of extensive and validated data on day to day and even weekly basis, and for extreme locations has been the major challenge in the empirical model.

Liu-Helmersson et al. (2016) developed a biological model to predict dengue epidemic possibility in $10 \mathrm{Eu}$ ropean cities based on the rise in temperature due to climatic changes predicted from 1901 to 2099. They linked the increased intensity and duration of dengue transmission to the high greenhouse gas emissions over the course of time in the $21^{\text {st }}$ century subsequently leading to rise in temperature making conditions hospitable to the vector for flourishment. The ecological niche model designed by Campbell et al. (2015) evaluated the occurrence data of Ae. aegypti and Ae. albopictus from 1950-2000 based on the temperature, rainfall and precipitation; and projected the potential distributions of these vectors in 2050, taking into consideration the climate change scenario. The model proposed a shift in the geographic distribution of mosquitoes by colonizing new areas crossing dispersal barriers, and expansion along the distribution edges when the environment becomes suitable for their reproduction and growth. Consequent to the ecological niche profiles of Aedes, they proposed that reorganization of the dispersal patterns may have a significant impact on the dengue transmission (Campbell et al., 2015). As per their predictions, Ae. aegypti had potential to expand in South and East Asia, Eastern North America, Australia and Africa; while Ae. albopictus could expand in Eastern North America, East Asia, Africa, Eastern and Southern South America, and majorly in Australia (Fig. 5).

Another approach used an indeterminate logical approach to anticipate the suitable regional and global emission habitats of $A e$. albopictus and characterized indecisive ranges to estimate the influence of selected meteorological measures (Proestos et al., 2015). They computed the habitat suitability index of $A e$. albopictus based on annual average precipitation, temperature, rainfall and relative humidity, and specified that by 2050 , approximately 2.4 billion people could be living in an area of high dengue risk transmitted by Ae. albopictus. 


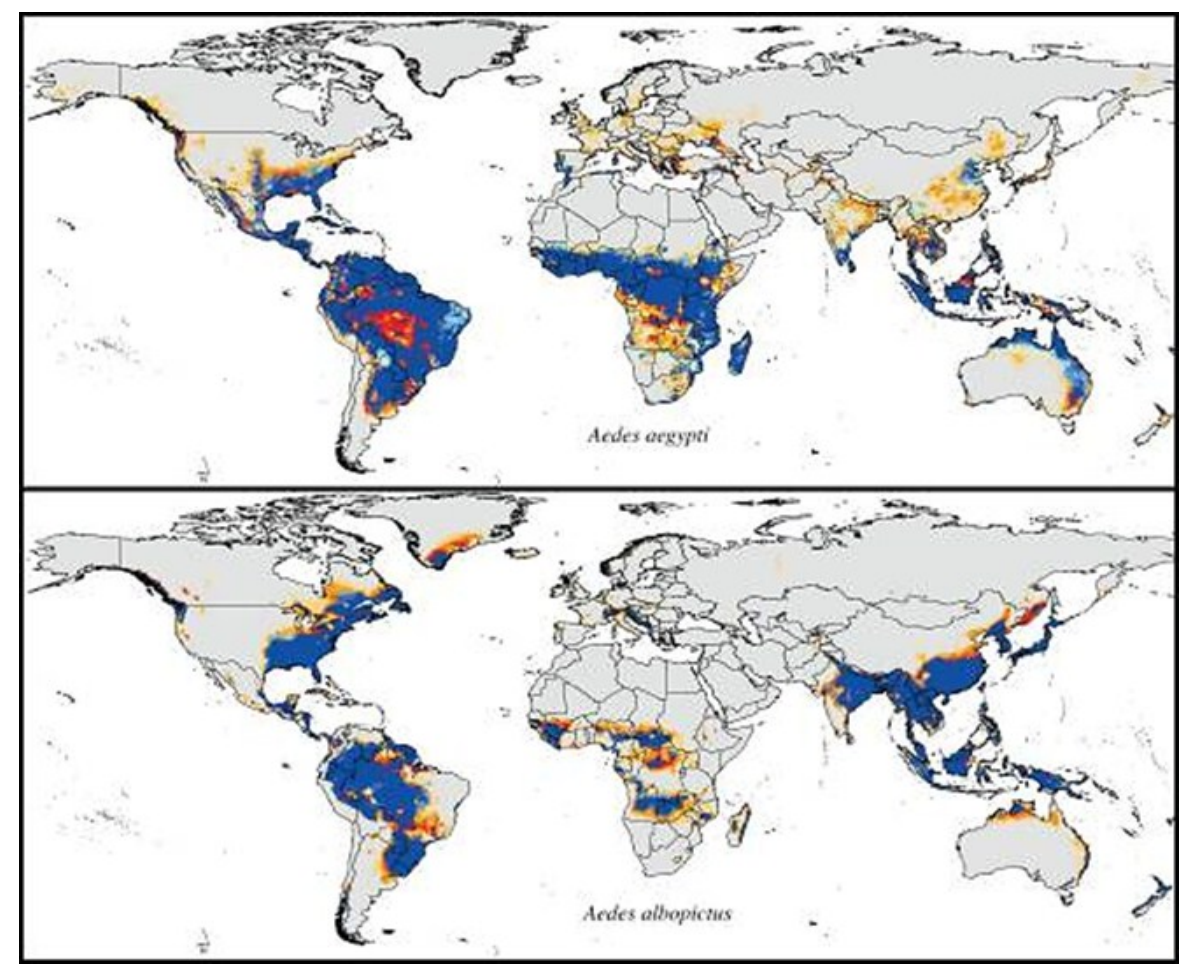

(Source: Campbell et al., 2015)

Fig. 5. Modelled potential distributional patterns of Ae. aegypti and Ae. albopictus under future conditions. Blue colour shows present-day-only distributional areas; the intensity of blue shading depicts model agreement (light blue denotes low and dark blue denotes high model agreement); shades of orange demonstrate future distributional potential (light orange denotes low and dark orange denotes high model agreement).

It has also been predicted that by 2061-2080, the worldwide area for Ae. aegypti multiplication would upsurge by $8 \%$ under modest and by $13 \%$ under high emissions and climate change (Monaghan et al., 2016). In addition, the individuals infected by the Ae. aegypti was forecasted to augment annually by $8-12 \%$ bearing in mind only climate change; by $59-65 \%$ when taken into consideration climate change along with a development pathway associated with population growth topping mid-century followed by a decline; and by $127-134 \%$ when taken in account climate change and a development pathway linked with high population increment (Messina et al., 2015).

Jain et al. (2019) designed a machine learning-based methodology to forecast dengue outbreaks in the fifty districts of Thailand. The model was based on several predictors, variables and their combinations; such as climatological data, clinical stats, lag variables of disease surveillance, socio-economic figures and the data regarding spatial dependence. Pineda-Cortel et al. (2019) used Autoregressive Integrated Moving Average models and inferred use of climatic variables as the predictor factors to forecast dengue incidence.

The changing climate and valuation circumstances provide consistent predictions that could be used in future models for the risks assessment of dengue transmission under different scenarios of ecological, topological, social, demographic and economic factors (Morin et al., 2013). This also includes quantifying some crucial variables and significant drivers; such as resources financed for the betterment of healthcare and related facilities in low and middle-income countries (Ebi, 2014).

The occurrence of dengue depends upon a multifarious factors. The analysis of different models predicting dengue prevalence reveals a need for dynamic modelling to understand the complex disease. The prediction based on the records of long-duration climatic data collected from a widespread geographical region, understanding of vector ecology, virus severity, and inclusion of socio-economic, demographic and other causative parameters in the study can help in dengue risk assessment. In fact, the estimation of delayed effects of climatic factors on the dengue occurrence in the tapped regions can assist in taking controlling and preventive measures beforehand enabling to fight this fast-growing disease.

\section{CHALLENGES IN PREDICTION OF DENGUE TRANSMISSION}

The ultimate challenge in predicting dengue transmission is how to fit the best model of future climate changes at the local level. Various suggestions and reports have been published by the Intergovernmental 
Panel on Climate Change (IPCC, 2019) covering multifarious causative factors underlying prospective greenhouse gas emissions leading to climate change. These reports suggest different scenarios; such as the novel and effectual technological development leading to speedy economic and population growth by 2050; high rise in population but with slower economic and technological developments; and average population and economic development with restricted sustainable answers to the economic, social and environment.

The panel recommended that no single model can be considered to account climate modelling uncertainties. Despite various confirmatory reports, the amplified dengue incidences; whether arose due to climate change (Patz et al., 1996) or because of socioeconomic changes in combination with ecologic and demographic changes (Gubler, 2011a; b); is still debatable. The incorporation of multiple etiological factors into integrated modelling is significant to determine the human risk to dengue (Beebe et al., 2009).

\section{Conclusion}

The geographical expansion of dengue vector; due to the complex interactions of climatic, socio-economic and demographic factors that impact mosquito breeding sites, distribution and generation time, human immunity, migration, and behavior; is expected to induce a greater and more severe burden of dengue in the economically poor and middle-income countries. The impoverished areas lack resources to stop/manage dengue infection and are experiencing heightened risks. Thus, operative strategies and procedures may play a key role to prepare and combat the disease incidences across varied geographic range. These comprise better-quality and coherent reconnaissance systems; upgraded and confirmatory vector control interventions; and increased awareness of Aedesborne diseases. In addition, adequate decision and policies could aid in the development of primary warning systems based on the environmental, social and demographic factors to formulate and implement preventive measures. Further, the impact of climate change on human health has necessitated revisiting global climate change policies and interventions. The increasing support for the research and development along with regular monitoring, can help recognize the current and predict the future distributions of Aedes and DENV better.

\section{REFERENCES}

1. Adams, B. and Kapan, D.D. (2009). Man bites mosquito: Understanding the contribution of human movement to vector-borne disease dynamics. PloS One, 4(8): p.e6763. https://doi.org/10.1371/journal.pone.0006763

2. Alshehri, M.S.A. and Saeed, M. (2013). Dengue fever outburst and its relationship with climatic factors. World Appl. Sci. J., 22(4): 506-515. 0.5829/idosi.wasj.2013.2 2.04 .443

3. Andraud, M., Hens, N. and Beutels, P. (2013). A simple periodic-forced model for dengue fitted to incidence data in Singapore. Math. Biosci., 244(1): 22-28.I https://doi.or g/10.1016/j.mbs.2013.04.001

4. Arunachalam, N., Murty, U., Kabilan, L., Balasubramanian, A., Thenmozhi, V., Narahari, D., Ravi, A. and Satyanarayana, K. (2004). Studies on dengue in rural areas of Kurnool District, Andhra Pradesh, India. J. Amer. Mosq. Contr. Assoc., 20(1): 87-90.

5. Aziz, AL., Dieng, H., Ahmad, A.H., Mahyoub, J.A., Turkistani, A.M., Mesed, H., Koshike, S., Satho, T., Salmah, M.C., Ahmad, H., Zuharah, W.F. and Ramli, A.S. (2012). Household survey of the container-breeding mosquitoes and climatic factors influencing the prevalence of Aedes aegypti (Diptera: Culicidae) in Makkah City, Saudi Arabia. Asian Pacific J. Trop. Biomed., 2(11): 849-857. https://doi.org/10.1016/S2221-1691(12)60242-1

6. Barbazan, P., Guiserix, M., Boonyuan, W., Tuntaprasart, W., Pontier, D. and Gonzalez, J.P. (2010). Modelling the effect of temperature on transmission of dengue. Med. Vet. Entomol., 24(1): 66-73. https://doi.org/10.1111/j.1365 $-2915.2009 .00848 . x$

7. Beebe, N.W., Cooper, R.D., Mottram, P. and Sweeney, A.W. (2009). Australia's dengue risk driven by human adaptation to climate change. PLoS Neglect. Trop. Dis., 3 (5): p.e429. https://doi.org/10.1371/journal.pntd.0000429

8. Bhatt, S., Gething, P.W., Brady, O.J., Messina, J.P., Farlow, A.W., Moyes, C.L., Drake, J.M., Brownstein, J.S., Hoen, A.G., Sankoh, O. and Myers, M.F. (2013). The global distribution and burden of dengue. Nature, 496 (7446): 504-507. https://doi.org/10.1038/nature12060

9. Brady, O.J., Gething, P.W., Bhatt, S., Messina, J.P., Brownstein, J.S., Hoen, A.G., Moyes, C.L., Farlow, A.W., Scott, T.W. and Hay, S.I. (2012). Refining the global spatial limits of dengue virus transmission by evidence-based consensus. PLoS Neglect. Trop. Dis., 6(8): p.e1760. https://doi.org/10.1371/journal.pntd.0001760

10.Campbell-Lendrum, D., Manga, L., Bagayoko, M. and Sommerfeld, J. (2015). Climate change and vector-borne diseases: What are the implications for public health research and policy? Philos. Trans. Royal Soc. B: Biol. Sci., 370(1665): p.20130552. https://doi.org/10.1098/rst b.20 13.0552

11.Carrington, L.B., Seifert, S.N., Willits, N.H., Lambrechts, L. and Scott, T.W. (2013a). Large diurnal temperature fluctuations negatively influence Aedes aegypti (Diptera: Culicidae) life-history traits. J. Med. Entomol., 50(1): 4351. https://doi.org/10.1603/ME11242

12.Carrington, L.B., Seifert, S.N., Armijos, M.V., Lambrechts, L. and Scott, T.W. (2013b). Reduction of Aedes aegypti vector competence for dengue virus under large temperature fluctuations. Amer. J. Trop. Med. Hyg., 88(4): 689697. https://doi.org/10.4269/ajtmh.12-0488

13.Carrington, L.B., Armijos, M.V., Lambrechts, L. and Scott, T.W., (2013c). Fluctuations at a low mean temperature accelerate dengue virus transmission by Aedes aegypti. PLoS Neglect. Trop. Dis., 7(4): p.e2190. https:// doi.org/10.1371/journal.pntd.0002190 
14.Chakravarti, A. and Kumaria, R. (2005). Ecoepidemiological analysis of dengue infection during an outbreak of dengue fever, India. Virol. J., 2(1): 32. https:// doi.org/10.1186/1743-422X-2-32

15.Chakravarti, A., Arora, R. and Luxemburger, C. (2012). Fifty years of dengue in India. Transact. Royal Soc. Trop. Med. Hyg., 106(5): 273-282. https://doi.org/10.1016/j.trstm h.2011.12.007

16.Chaturvedi, U.C. and Nagar, R. (2008). Dengue and dengue haemorrhagic fever: Indian perspective. J. Biosci., 33 (4): 429-441. https://www.ias.ac.in/article/fulltext/jbsc/0 3 3/0 4/0429-0441

17.Chaves, L.F. and Koenraadt, C.J. (2010). Climate change and highland malaria: Fresh air for a hot debate. Quarterly Rev. Biol., 85(1): 27-55. https://doi.org/10.1086/650284

18.Chaves, L.F., Scott, T.W., Morrison, A.C. and Takada, T. (2014). Hot temperatures can force delayed mosquito outbreaks via sequential changes in Aedes aegypti demographic parameters in auto-correlated environments. Acta. Trop., 129: 15-24. https://doi.org/10.1016/j.actatropic a.20 13.02.025

19.Chen, S.C. and Hsieh, M.H. (2012). Modeling the transmission dynamics of dengue fever: implications of temperature effects. Sci. Total Environ., 431: 385-391. https:// doi.org/10.1016/j.scitotenv.2012.05.012

20.Chikaki, E. and Ishikawa, H. (2009). A dengue transmission model in Thailand considering sequential infections with all four serotypes. J. Infect. Dev. Countr., 3(9): 711722. https://doi.org/10.3855/jidc.616

21.Choi, Y., Tang, C.S., Mclver, L., Hashizume, M., Chan, V., Abeyasinghe, R.R., Iddings, S. and Huy, R., (2016). Effects of weather factors on dengue fever incidence and implications for interventions in Cambodia. BMC Publ. Hlth., 16(1): 1-7. https://doi.org/10.1186/s12889-016-2923-2

22.Descloux, E., Mangeas, M., Menkes, C.E., Lengaigne, M., Leroy, A., Tehei, T., Guillaumot, L., Teurlai, M., Gourinat, A.C., Benzler, J. and Pfannstiel, A. (2012). Climate-based models for understanding and forecasting dengue epidemics. PLoS Neglect. Trop. Dis., 6(2): p.e1470. https:// doi.org/10.1371/journal.pntd.0001470

23.Earnest, A., Tan, S.B. and Wilder-Smith, A. (2012). Meteorological factors and El Nino Southern Oscillation are independently associated with dengue infections. Epidemiol. Infect. 140(7): 1244-1251. https:// doi.org/10.1017/S095026881100183X

24.Ebi, K.L. (2014). Health in the new scenarios for climate change research. Internat. J. Environ. Res. Publ. HIth., 11: 30-46. https://doi.org/10.3390/ijerph110100030

25.Elliott, P. and Wartenberg, D. (2004). Spatial epidemiology: Current approaches and future challenges. Environ. HIth. Perspect., 112(9): 998-1006. https://doi.org/10.1289/ ehp. 6735

26.Focks, D.A., Daniels, E., Haile, D.G. and Keesling, J.E. (1995). A simulation model of the epidemiology of urban dengue fever: Literature analysis, model development, preliminary validation, and samples of simulation results. Amer. J. Trop. Med. Hyg., 53(5): 489-506. https:// doi.org/10.4269/ajtmh.1995.53.489

27.Ghani, M.H., Humaira, M., Khushk, I.A., Ghouri, A.A., Memon, Y. and Memon, M.A. (2008). Dengue Virus Outbreak in the Year 2006 at a Tertiary Care Centre in Sindh.
J. Liaquat Univ. Med. HIth. Sci., 7(2): 71-74.

28.Gharbi, M., Quenel, P., Gustave, J., Cassadou, S., La Ruche, G., Girdary, L. and Marrama, L. (2011). Time series analysis of dengue incidence in Guadeloupe, French West Indies: Forecasting models using climate variables as predictors. BMC Infect. Dis., 11(166): 1-13. https:// doi.org/10.1186/1471-2334-11-166

29.Githeko, A.K. (2012). Advances in developing a climatebased dengue outbreak models in Dhaka, Bangladesh: Challenges and opportunities. Ind. J. of Med. Res., 136 (1): 7-9.

30.Gomes, A.F., Nobre, A.A. and Cruz, O.G. (2012). Temporal analysis of the relationship between dengue and meteorological variables in the city of Rio de Janeiro, Brazil, 2001-2009. Cad. Saúde Pública, 28: 2189-2197.

31.Gubler D.J. (1997). Dengue and dengue hemorrhag-ic fever: its history and resurgence as a global public health problem. Dengue and dengue hemorrhagic fever. London, United Kingdom; CAB International, pp. 1-22.

32.Gubler, D.J. (1998). Dengue and dengue hemorrhagic fever. Clin. Microbiol. Rev., 11(3): 480-496. https:// doi.org/10.1128/CMR.11.3.480

33.Gubler, D.J. (2011a). Dengue, urbanization and globalization: The unholy trinity of the 21st century. Trop. Med. Hlth., 39(4): 3-11. https://doi.org/10.2149/tmh.2011-S05

34.Gubler, D.J. (2011b). Emerging vector-borne flavivirus diseases: are vaccines the solution? Expert Rev. Vaccines, 10(5): 563-565. https://doi.org/10.1586/erv.11.35

35.Gubler D.J. (2012). The economic burden of dengue. Amer. J. Trop. Med. Hyg., 86:743-744.

36.Gubler, D.J. and Trent, D.W. (1993). Emergence of epidemic dengue/dengue hemorrhagic fever as a public health problem in the Americas. Infect. Agents Dis., 2(6): 383-393.

37.Gubler, D.J., Reiter, P., Ebi, K.L., Yap, W., Nasci, R. and Patz, J.A. (2001). Climate variability and change in the United States: Potential impacts on vector-and rodentborne diseases. Environ. Hith. Perspect., 109(2): 223-233. https://doi.org/10.1289/ehp.109-1240669

38. Halasa, Y.A., Shepard, D.S. and Zeng, W. (2012). Economic cost of dengue in Puerto Rico. Amer. J. Trop. Med. Hyg., 86(5),:745-752.https://doi.org/10.4269/ajtmh.201 2.1 1-0784

39. Hales, S., De Wet, N., Maindonald, J. and Woodward, A. (2002). Potential effect of population and climate changes on global distribution of dengue fever: An empirical model. The Lancet, 360(9336): 830-834. https://doi.org/10.10 16/S0140-6736(02)09964-6

40.Halstead, S.B. (2008). Dengue virus-mosquito interactions. Annu. Rev. Entomol., 53: 273-291. https:// doi.org/10.1146/annurev.ento.53.103106.093326

41.Hii, Y.L., Rocklöv J., Ng N., Tang C.S., Pang, F.Y. and Sauerborn R. (2009) Climate variability and increase in intensity and magnitude of dengue incidence in Singapore. Glob. Hlth. Action. 2: 1. doi: 10.3402/gha.v2i0.2036.

42. Howe (1977). A world geography of human diseases. New York, N.Y: Academic Press, Inc., pp. 621.

43. Hu, W., Clements, A., Williams, G., Tong, S. and Mengersen, K. (2012). Spatial patterns and socioecological drivers of dengue fever transmission in Queensland, 
Australia. Environ. Hith. Perspect., 120(2): 260-266. https://doi.org/10.1289/ehp.1003270

44.IPCC. (2019) Working Group II: Impacts, adaptation and vulnerability.http://www.ipcc.ch/ipccreports/tar/wg2/index. php?idp $=361$

45.Jain, R., Sontisirikit, S., lamsirithaworn, S. and Prendinger, H. (2019). Prediction of dengue outbreaks based on disease surveillance, meteorological and socio-economic data. BMC Infect. Dis., 19(1):1-16. https://doi.org/10.1186/ s12879-019-3874-x

46.Johansson, M.A., Dominici, F. and Glass, G.E. (2009a). Local and global effects of climate on dengue transmission in Puerto Rico. PLoS Neglect. Trop. Dis., 3(2): p.e382. https://doi.org/10.1371/journal.pntd.0000382

47.Johansson, M.A., Cummings, D.A. and Glass, G.E. (2009b). Multiyear climate variability and dengue-EI Nino southern oscillation, weather, and dengue incidence in Puerto Rico, Mexico, and Thailand: A longitudinal data analysis. PLoS Med., 6(11): p.e1000168. https:// doi.org/10.1371/journal.pmed.1000168

48.Karim, M.N., Munshi, S.U., Anwar, N. and Alam, M.S. (2012). Climatic factors influencing dengue cases in Dhaka city: A model for dengue prediction. Ind. J. Med. Res., 136(1): 32-39.

49.Khormi, H.M., and Kumar, L. (2012). Assessing the risk for dengue fever based on socio-economic and environmental variables in a geographical information system environment. Geospat. Hlth., 6(2): 171-176. http://www.geospa tialhealth.unina.it/

50.Koh, B.K., Ng, L.C., Kita, Y., Tang, C.S., Ang, L.W., Wong, K.Y., James, L. and Goh, K.T. (2008). The 2005 dengue epidemic in Singapore: epidemiology, prevention and control. Annals Acad. Med. Singapore, 37(7), 538.

51.Kuno, G. (1995). Review of the factors modulating dengue transmission. Epidemiol. Rev., 17(2): 321-335. https:// doi.org/10.1093/oxfordjournals.epirev.a036196

52.Lee, H., Kim, J.E., Lee, S. and Lee, C.H. (2018). Potential effects of climate change on dengue transmission dynamics in Korea. PLoS One, 13(6): p.e0199205. https:// doi.org/10.1371/journal.pone.0199205

53.Liu-Helmersson, J., Quam, M., Wilder-Smith, A., Stenlund, H., Ebi, K., Massad, E. and Rocklöv, J. (2016). Climate change and Aedes vectors: 21st century projections for dengue transmission in Europe. EBioMedicine, 7: 267277. https://doi.org/10.1016/j.ebiom.2016.03.046

54.Lu, L., Lin, H., Tian, L., Yang, W., Sun, J. and Liu, Q. (2009). Time series analysis of dengue fever and weather in Guangzhou, China. BMC Publ. Hlth., 9(1),395. https:// doi.org/10.1186/1471-2458-9-395

55.McMichael, A.J. and Haines, A., (1997). Global climate change: The potential effects on health. British Med. J., 315(7111): 805-809. https://doi.org/10.1136/ bmj.315.7111.805

56.McMichael, A.J., Woodruff, R.E. and Hales, S. (2006). Climate change and human health: Present and future risks. The Lancet, 367(9513): 859-869. https:// doi.org/10.1016/S0140-6736(06)68079-3

57.McSherry, J.A. (1982). Some medical aspects of the Darien scheme: Was it dengue? Scottish Med. J., 27(2): 183184. https://doi.org/10.1177/003693308202700215.

58.Messina, J.P., Brady, O.J., Pigott, D.M., Golding, N., Kra- emer, M.U., Scott, T.W., Wint, G.W., Smith, D.L. and Hay, S.I. (2015). The many projected futures of dengue. Nature Rev. Microbiol., 13(4): 230-239. https://doi.org/10.1038/ nrmicro3430

59.Monaghan, A.J., Morin, C.W., Steinhoff, D.F., Wilhelmi, O., Hayden, M., Quattrochi, D.A., Reiskind, M., Lloyd, A.L., Smith, K., Schmidt, C.A. and Scalf, P.E. (2016). On the seasonal occurrence and abundance of the Zika virus vector mosquito Aedes aegypti in the contiguous United States. PLoS Current Outbreaks, 16(1). http:// dx.doi.org/10.1371/currents.outbreaks.50dfc7f46798675f c 63e7d7da 563da76.

60.Morin, C.W., Comrie, A.C. and Ernst, K. (2013). Climate and dengue transmission: evidence and implications. Environ. Health. Perspect. 121(11-12):1264-1272. https://doi.org/10.1289/ehp.1306556

61.Mustafa, M. S., Rasotgi, V., Jain, S. and Gupta, V. (2015). Discovery of fifth serotype of dengue virus (DENV-5): A new public health dilemma in dengue control. Med. J. Armed Forces India: 71(1): 67-70. https://doi.org/10.1016/ j.mjafi.2014.09.011

62.Nagao, Y., Thavara, U., Chitnumsup, P., Tawatsin, A., Chansang, C. and Campbell $\square$ Lendrum, D. (2003). Climatic and social risk factors for Aedes infestation in rural Thailand. Trop. Med. Internat. HIth., 8(7): 650-659. https:// doi.org/10.1046/j.1365-3156.2003.01075.x

63.National Vector Borne Disease Control Programme (NVBDCP) (2020). Dengue/DHF situation in India. [Online] Available at: https://nvbdcp.gov.in/index4.php? lang $=1$ andlevel $=0$ andlinkid $=431$ andlid $=3715 \quad$ (Accessed on 18 August, 2020).

64.Nobuchi, H. (1979). The symptoms of a dengue-like illness recorded in a Chinese medical encyclopedia. Kanpo Rinsho, 26:422-425.

65.Pandya, G. (1982). Prevalence of dengue infections in India. Defence Sci. J., 4: 359-370.

66.Patz, J.A., Epstein, P.R., Burke, T.A. and Balbus, J.M. (1996). Global climate change and emerging infectious diseases. Jama, 275(3),217-223.doi:10.1001/jama.1996.0 3530270057032

67.Pineda-Cortel, M.R.B., Clemente, B.M. and Nga, P.T.T. (2019). Modeling and predicting dengue fever cases in key regions of the Philippines using remote sensing data. Asian. Pacific. J. Trop. Med., 12(2): 60-66. doi: 10.4103/1995-7645.250838

68.Pinto, E., Coelho, M., Oliver, L. and Massad, E. (2011). The influence of climate variables on dengue in Singapore. Int. J. Environ. Health. Res, 21(6): 415-426. https:// doi.org/10.1080/09603123.2011.572279

69.Proestos, Y., Christophides, G.K., Ergüler, K., Tanarhte, M., Waldock, J. and Lelieveld, J., (2015). Present and future projections of habitat suitability of the Asian tiger mosquito, a vector of viral pathogens, from global climate simulation. Philos. Transact. Royal Soc. B: Biol. Sci., 370 (1665): p.20130554. https://doi.org/10.1098/rstb.20 13.0554

70.Promprou, S., Jaroensutasinee, M. and Jaroensutasinee, K. (2011). Climatic factors affecting dengue haemorrhagic fever incidence in Southern Thailand. Dengue Bulletin, 29, 41-48.

71.Rabaa, M.A., Hang, V.T.T., Wills, B., Farrar, J., Simmons, 
C.P. and Holmes, E.C. (2010). Phylogeography of recently emerged DENV-2 in southern Vietnam. PLoS Negl. Trop. Dis, 4(7), p.e766. https://doi.org/10.1371/journal.p ntd.0000766

72.Ramachandran, V.G., Roy, P., Das, S., Mogha, N.S. and Bansal, A.K. (2016). Empirical model for estimating dengue incidence using temperature, rainfall, and relative humidity: A 19-year retrospective analysis in East Delhi. Epidemiol. HIth., 38. doi: 10.4178/epih.e2016052

73.Ramakrishnan, S.P., Gelfand, H.M., Bose, P.N., Sehgal, P.N. and Mukherjee, R.N. (1964). The epidemic of acute haemorrhagic fever, Calcutta, 1963: Epidemiology Inquiry. Ind. J. Med. Res., 52: 633-650.

74.Reiner Jr, R.c., Stoddard, S.T. and Scott T.W. (2014). Socially structured human movement shapes dengue transmission despite the diffusive effect of mosquito dispersal. Epidemics, 6: 30-36. https://doi.org/10.1016/ j.epidem.2013.12.003

75.Reiter, P., Lathrop, S., Bunning, M., Biggerstaff, B., Singer, D., Tiwari, T., Baber, L., Amador, M., Thirion, J., Hayes, J. and Seca, C. (2003). Texas lifestyle limits transmission of dengue virus. Emerg. Infect. Dis., 9(1): 86-89. doi: 10.3201/eid0901.020220

76.Sarfraz, M.S., Tripathi, N.K., Tipdecho, T., Thongbu, T., Kerdthong, P. and Souris, M. (2012). Analyzing the spatio -temporal relationship between dengue vector larval density and land-use using factor analysis and spatial ring mapping. BMC Publ. HIth., 12(1): 1-19.

77.Scott, T.W. and Morrison, A. C. (2010). Vector dynamics and transmission of dengue virus: implications for dengue surveillance and prevention strategies: Vector dynamics and dengue prevention. Curr. Top. Microbiol. Immunol., 338: 115-128. doi: 10.1007/978-3-642-02215-9_9

78.Scott, T.W., Morrison, A.C., Lorenz, L.H., Clark, G.G., Strickman, D., Kittayapong, P., Zhou, H. and Edman, J.D. (2000). Longitudinal studies of Aedes aegypti (Diptera: Culicidae) in Thailand and Puerto Rico: Population dynamics. J. Med. Entomol., 37(1): 77-88. https:// doi.org/10.1603/0022-2585-37.1.77

79.Shil, P. (2019). Rainfall and dengue occurrences in India during 2010-2016. Biomed. Res. J., 6(2): 56. doi: 10.4103/BMRJ.BMRJ_15_19

80.Sriprom, M., Chalvet-Monfray, K., Chaimane, T., Vongsawat, K. and Bicout, D.J. (2010). Monthly district level risk of dengue occurrences in Sakon Nakhon Province, Thailand. Sci. Total Environ., 408(22): 5521-5528. https:// doi.org/10.1016/j.scitotenv.2010.08.024

81.Stoddard, S.T., Morrison, A.C., Vazquez-Prokopec, G.M., Soldan, V.P., Kochel, T.J., Kitron, U., Elder, J.P. and Scott, T.W. (2009). The role of human movement in the transmission of vector-borne pathogens. PLoS Neglect. Trop. Dis., 3(7): p.e481. https://doi.org/10.1371/ journal.pntd.0000481

82.Stoddard, S.T., Forshey, B.M., Morrison, A.C., PazSoldan, V.A., Vazquez-Prokopec, G.M., Astete, H., Reiner, R.C., Vilcarromero, S., Elder, J.P., Halsey, E.S. and Kochel, T.J. (2013). House-to-house human movement drives dengue virus transmission. Proc. Natl. Acad. Sci., 110(3): 994-999. https://doi.org/10.1073/pnas.12 13349110

83.Thammapalo, S., Chongsuwiwatwong, V., McNeil, D. and Geater, A. (2005). The climatic factors influencing the occurrence of dengue hemorrhagic fever in Thailand. Southeast Asian J. Trop. Med. Publ. Hith., 36(1): 191-196.

84.Tipayamongkholgul, M. and Lisakulruk, S. (2011). Sociogeographical factors in vulnerability to dengue in Thai villages: A spatial regression analysis. Geospat. Hith, 5 (2): 191-198. http://www.geospatialhealth.unina.it/

85.Tuladhar, R., Singh, A., Varma, A. and Choudhary, D.K., 2019. Climatic factors influencing dengue incidence in an epidemic area of Nepal. BMC Res. Notes, 12(1):1-7. https://doi.org/10.1186/s13104-019-4185-4

86.Vazquez-Prokopec, G.M., Stoddard, S.T., Paz-Soldan, V., Morrison, A.C., Elder, J.P., Kochel, T.J., Scott, T.W. and Kitron, U., (2009). Usefulness of commercially available GPS data-loggers for tracking human movement and exposure to dengue virus. Internat. J. Hith. Geograph., 8 (1): 68. https://doi.org/10.1186/1476-072X-8-68

87.Walker, K.R., Joy, T.K., Ellers-Kirk, C. and Ramberg, F.B. (2011). Human and environmental factors affecting Aedes aegypti distribution in an arid urban environment. J. Amer. Mosq. Contr. Assoc., 27(2): 135-141. https://doi.org/10.2 987/10-6078.1

88.Watson, J.T., Gayer, M. and Connolly, M.A. (2007). Epidemics after natural disasters. Emerg. Infect. Dis., 13(1): 1-5. doi: 10.3201/eid1301.060779

89.Wearing, H.J. and Rohani, P. (2006). Ecological and immunological determinants of dengue epidemics. Proc. Natl. Acad. Sci., 103(31): 11802-11807. https:// doi.org/10.1073/pnas.0602960103

90.WHO (World Health Organization) (2019a). WHO region of the Americas records highest number of dengue cases in history; cases spike in other regions. Available at https://www.who.int/news-room/detail/21-11-2019-whoregion-of-the-americas-records-highest-number-ofdengue-cases-in-history-cases-spike-in-other-regions

91.WHO (World Health Organization) (2019b). Dengue Situation Update Number 559. WHO.

92.WHO (World Health Organization) (2020a). Dengue and severe dengue. Available at http://www.who.int/ mediacentre/factsheets/fs117/en/.

93.WHO (World Health Organization) (2020b). Dengue Situation Update Number 597. WHO.

94.Win, T. (2013). Dengue fever cases hit a high in parts of Southeast Asia. Retrieved from Thomson Reuters Foundation: https://news.trust.org/item/20130625114148-6jw h n/

95.Yuan, H.Y., Wen, T.H., Kung, Y.H., Tsou, H.H., Chen, C.H., Chen, L.W. and Lin, P.S. (2019). Prediction of annual dengue incidence by hydro-climatic extremes for southern Taiwan. Internat. J. Biometeorol., 63(2): 259-268. https://doi.org/10.1007/s00484-018-01659-w 